\title{
The Role of Complementary and Alternative Medicine for the Management of Fibroids and Associated Symptomatology
}

\author{
Nick Dalton-Brewer ${ }^{1}$ \\ Published online: 25 April 2016 \\ (C) The Author(s) 2016. This article is published with open access at Springerlink.com
}

\begin{abstract}
This article discusses the role of complementary and alternative medicine (CAM) in the management of fibroids and associated symptomatology. Since there is such a paucity of direct research related to fibroids, conditions that are implicated in the causation of uterine fibroids and symptomatology that CAM treatments may or have been shown to make a difference are also considered.
\end{abstract}

Keywords Uterine fibroids · Infertility · Acupuncture ·

CAM $\cdot$ Cardiovascular disease $\cdot$ Obesity

\section{Introduction}

Uterine fibroids are a common condition affecting women in their reproductive and post-reproductive years, with an estimated lifetime incidence of $50 \%$ in white women and $80 \%$ in black women.

Complementary and alternative medicine (CAM) is broadly defined as systems of medicine that fall outside of mainstream care and are external to the politically dominant health system practices [1]. In this definition, both complementary and alternative medicines are used interchangeably.

The National Centre for Complementary and Integrative Health (NCCIH) expands this definition, stating that 'complementary medicine is used together with conventional medicine and alternative medicine is used in place of conventional

This article is part of the Topical Collection on Uterine Fibroids

Nick Dalton-Brewer nick.dalton-brewer@nhs.net

1 King's Hewitt Fertility Centre, Unit 6 Business Park, King's College Hospital NHS Foundation Trust, London SE5 9RS, UK medicine' [2]. The boundaries between CAM and conventional medicine are not absolute, and specific CAM practices may, over time, become widely accepted. To confuse the matter further, certain therapies that are considered as CAM in the West are part of conventional medicine in the East. For example, acupuncture and Chinese herbal medicine are part of the conventional medical system in China. For purposes of this article, we will discuss only those therapies that are CAM as defined in the West.

Recent data shows that patient choice is integrative in that they are more likely to use both conventional medicine and CAM. Women are more likely to use CAM than men [3]. CAM use is generally greater in white and middle-class women with a higher education compared to black women or women living in areas of depravity [4].

A trial of 150,000 men and women registered with a Dutch health insurer reported that those who used integrated CAM/ conventional clinic services are more likely to live longer. Interestingly, the health care cost to the integrated clinics was lower than non-integrated clinics, suggesting a role for an integrated service model in the prevention of long-term health problems [5].

\section{Aetiopathogenesis Related to CAM}

Diet

Dietary therapy is one of the top motivations a woman has for visiting a CAM practitioner [6].

The incidence of uterine fibroids has been shown to be greater in populations who consume more red meats such as beef and ham and alcohol. Women who drink a beer a day or more increase the risk of developing uterine fibroids by more than $50 \%$ [7]. On the other hand, dairy consumption appears 
to reduce the risk of fibroids, thus suggesting a role for calcium, magnesium and phosphorus in the pathogenesis of fibroids; both calcium and butyric acid inhibit cell proliferation [8].

A diet low in fruits and vegetables has been associated with an increased risk of developing fibroids [9]. Moreover, women who consume more citrus fruits are less likely to develop fibroids, possibly due to the anti-proliferative effect of flavonoids [9].

\section{Isoflavones}

Isoflavones are a branch of flavanoids and are mostly produced by the monophyletic family, Fabaceae, to which Chinese herbal medicine (CHM) such as Puerariae Lobata Radix (Gegen), and foods such as soyabeans, and other legumes belong. Isoflavone consumption differs; in the West, $2 \mathrm{mg}$ per day is usual [10]. In the East, up to $50 \mathrm{mg}$ per day can be consumed [11]. There is also a significant difference between herb and food isoflavone content. The main dietary source of isoflavones is soyabean; one half a cup will yield around $47 \mathrm{mg}$ of isoflavones [12]. The yield from Radix Paeoniae Rubra (Chi Shao) however is about 30 times higher [12].

Isoflavones contain very small amounts of phytoestrogens that are weakly estrogenic compounds. Moreover, they are both estrogenic and anti-estrogenic depending on cell type and also have anti-oxidant properties, and perhaps, this may explain why they have not been shown to have an association or causation with uterine fibroids [13].

The flavones apigenin and luteolin can induce inhibition of uterine fibroid growth by promoting apoptosis, and quercetin, the main fruit flavonoid and anti-oxidant, also displays proapoptic effect on tumour cells $[14,15]$. The ability of quercetin to prevent growths in human cancer cell lines with virtually no side effects to normal cells has made it an attractive candidate for further investigation [16].

Vitamin D is associated with uterine fibroids and is obtained through diet and sun exposure. Dietary sources of vitamin D include fatty fish like salmon and tuna and fortified milk. The recommended daily allowance is $20 \mathrm{ng} / \mathrm{ml}$ (600 IU) of vitamin D a day for people under 70 and over 12 months [17]. In rats, high doses of vitamin D3 shrank uterine fibroids by as much as $75 \%$, suggesting a role for vitamin D3. Although the doses were comparatively much larger than the recommended daily intake for humans, they were still within the limits considered safe [18].

Serum vitamin D levels have been correlated with fibroid size; deficiency correlated with the largest fibroids, whereas the highest serum vitamin D levels correlated with the smallest fibroids. Total fibroid volume correlated inversely with vitamin $\mathrm{D}$ in African American women. An inverse correlation was also observed in Caucasians but was not significant $[19 \cdot \bullet]$.

Vitamin A has also been investigated, and a dosedependent relationship was observed between vitamin A and the formation of uterine fibroids [20]. Animal sources of vitamin A appear to be primarily responsible and not sources derived from fruit or vegetables [9]. The anti-oxidant properties of vitamins $\mathrm{C}$ and $\mathrm{E}$ have not shown any association however [9].

\section{Stress}

Stress is a threat to homeostasis. Chronic life stress is characterised by reward eating (consumption of high-energy dense and palatable foods), elevation of cortisol, and longterm weight gain correlates with the incidence of uterine fibroids [21-24].

Increases in cortisol and insulin may be a natural somatic protective response to stress, wherein the stress response both causes and is caused by a threat to homeostasis; i.e. the mechanistic trail may be convoluted. For example, stress increases activities associated with pleasure such as reward eating in order to inhibit the hypothalamic-pituitary-adrenal axis (HPA) as protective mechanism [25]. The consequent chronic suppression of cortisol levels may eventually cause insulin resistance, which in turn may result in the development of obesity, hypertension and atherosclerosis; all of which are implicated in fibroid growth [26].

\section{Hypertension}

Evidence suggests that hypertension is involved in the pathogenesis of fibroids and precedes the development of fibroids [27]. Hypertension is significantly more likely in women with fibroids than without, and the risk of fibroid growth increases with blood pressure, in both users and non-users of hypertensive medication. For every diastolic increase of $10 \mathrm{mmHG}$, the risk of fibroid growth increases by 8 and $10 \%$, respectively $[28,29]$. Faerstein et al. postulated that elevated blood pressure may cause smooth muscle injury and/or secretion of cytokines similarly to that found in the pathogenesis of atherosclerosis [28].

\section{Atherosclerosis}

Atherosclerosis and uterine fibroids are both smooth muscle, monoclonal growths which may in part explain their association. High-density lipids (HDLs) which are protective of atherosclerotic changes are lower in women with fibroids than in women without, and thicker carotid intima-media have been shown to be positively associated with uterine fibroids [28, 30•]. 


\section{Obesity}

The risk of developing a fibroid is between twofold and threefold in obese patients [31]. Elevated BMI and obesity correlate with patients who have both fibroids and hypertension. However, obesity does not correlate with the number of fibroids within the uterus, indicating that in addition to gonadotropins, the growth of uterine fibroids may involve other factors [32-34].

\section{Adipokines and Renin-Aldosterone-Angiotensin System}

Both adipokines and the renin-aldosterone-angiotensin system (RAS) are expressed in the reproductive system, and increase in expression may be implicated in the pathogenesis of uterine growths and their recurrence [35-37].

The presence of uterine fibroids is associated with significantly decreased levels of the adiponectin [38]. Although adiponectin is exclusively secreted by adipose tissue, yet its expression is inversely correlated with body fat. Low adiponectin levels are implicated in the development of atherosclerosis, obesity and insulin resistance [39].

\section{CAM Therapies for Management of Uterine Fibroids}

\section{Dietary Therapy}

Diets related to the pathogenesis of fibroids such as red meats and high-energy dense foods should be avoided, whereas diets which prevent fibroid pathogenesis such as flavonoids, oily fish, green vegetables, citrus fruits, soya and broad beans should be promoted. These modifications not only have direct effects on fibroids but on related mechanisms. For example, hypertension is implicated in pathogenesis and reducing sodium levels can reduce blood pressure. A treatment strategy that excludes red meat, fat and animal fat, and restricts diet to fruits vegetables and poultry, and reduces sodium intake can thus reduce blood pressure and may also exert a protective effect on fibroid growth [40].

A suggested dietary therapy is outlined in Table 1. Whilst the recommendations are based on direct and indirect pathogenesis associations, they have not been subjected to large-scale trials.

\section{Herbal Medicine}

The first record of CHM in gynaecology (the treatment of fertility) was written in 200 AD. However, the modern construction of a herbal formula is still based on the traditional criteria insofar as the phytokinetics and dynamics of the herbs is concerned. Integrating a medical system can prove beneficial to patients, for example, using clomiphene citrate with a traditional formula to treat anovulatory infertility arising from polycystic ovarian syndrome (PCOS) can achieve better results than using either CHM or clomiphene citrate alone [41].

\section{Gui Zhi Fu Ling Tang Ramulus cinnomomi and Poriae cocos decoction}

The most commonly used traditional Chinese medicine (TCM) formula to treat uterine fibroids is Gui Zhi Fu Ling Tang (GFLT) [42]. This formula is effective in the treatment of dysmenorrhea either as a stand-alone treatment or in combination with progesterone receptor modulator such as mifepristone. The combination GFLT mifepristone therapy was shown to be more effective than using mifepristone alone [43•]. Three of the herbs used are known to be antiproliferative and are involved in tumour cell apoptosis and induction of follistatin, Mu Dan Pi (Cortex Moutan), Chi Shao (Radix Paeoniae Rubra), and Tao Ren (Semen Persicae) [44-46].

\section{Danshen Gegen decoction (Salviae Miltiorrhizae Radix et Rhizome and Purariae Lobatae Radix decoction)}

The CHM formula Danshen Gegen decoction (DGD) has a long history of use and recently has been investigated for its anti-atherosclerotic effects. Investigative results into DGD indicate that it positively modulates key early events in atherosclerosis [47-49]. The main active components in Danshen and Gegen, tanshinones and genistein, respectively, are most likely responsible for the effects of DGD, although other factors in the formula may also be involved.

\section{Genistein}

The isoflavone genistein has a number of properties involved in the inhibition atherosclerosis. Genistein is an antiinflammatory and modulates vascular inflammation [50]. Genistein also inhibits tyrosine kinases, enzymes involved in cellular growth and proliferation signal cascade; blocks platelet aggregation; and modulates genes related to cell cycle and apoptosis [51]. In addition, genistein also modulates nuclear factor-kappa B (NFkB). As a result, genistein may also be able to mediate uterine fibroid growth [52].

\section{Tanshinones}

The flavonoid tanshinone IIA is derived from Danshen (Salviae Miltiorrhizae Radix et Rhizome), a herb used in the treatment of hypertension, cardiovascular disease and hypertension, cancer and liver damage [53]. 
Table 1 Dietary therapy and advice

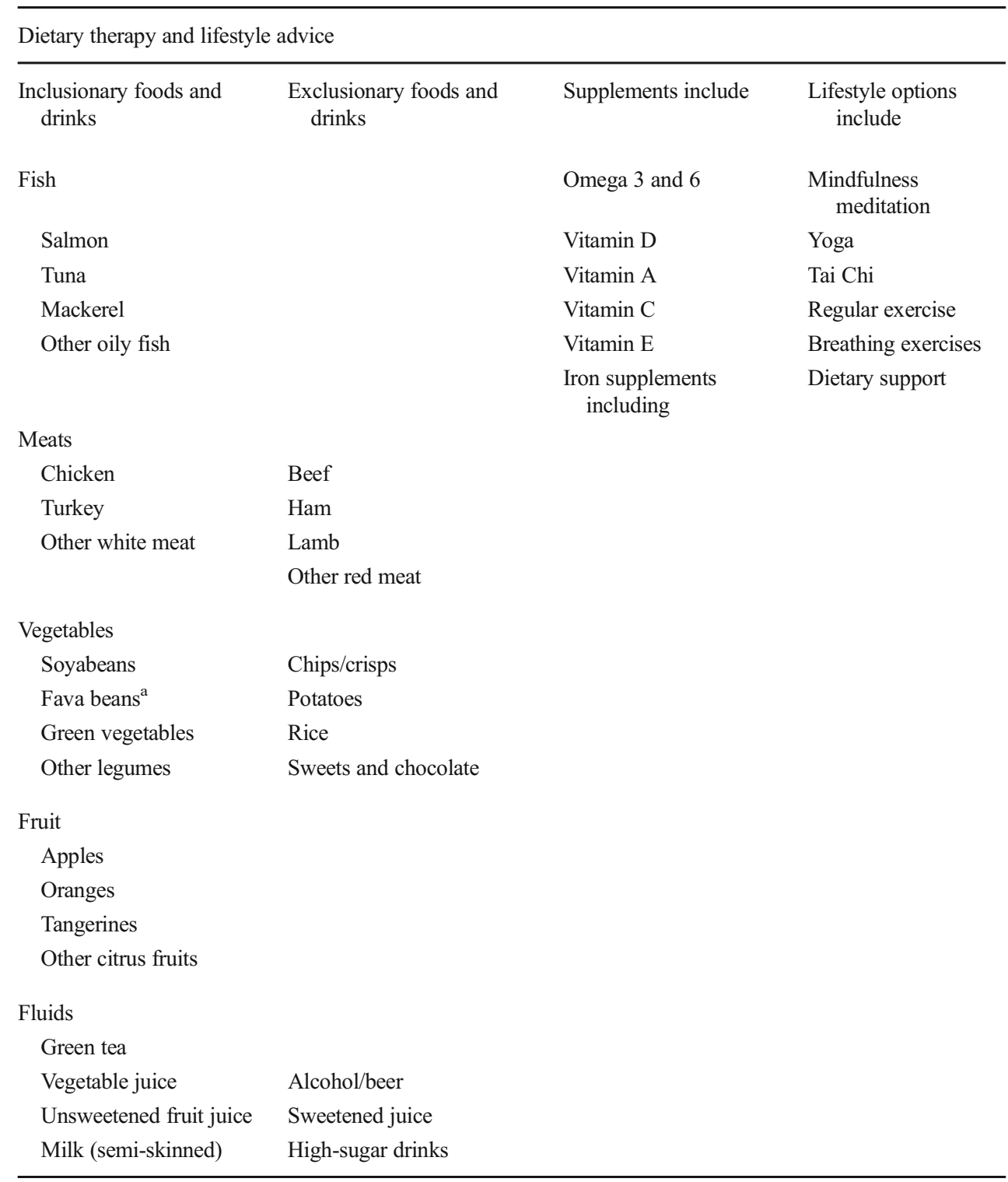

${ }^{a}$ Not to be consumed by people with the hereditable condition of Favism
Tanshinone IIA attenuates atherosclerosis [54]. Its effects include downregulation of adhesion molecules, improvement of microcirculation by inducing endothelium-dependent vasodilatation in coronary arterioles through a range of neuromodulators including endothelial nitric oxide synthase (eNOS) and angiotensin II [55, 56]. Interestingly, it also inhibits vascular smooth muscle cell proliferation and decreases intimal thickening through mechanisms involving MAPK signalling pathway [57].

\section{Green Tea (Camellia sinensis)}

Twenty-five percent of green tea is comprised of the flavanols and catechins, and epigallocatechin-3-gallate (EGCG) is extracted from this group. A small randomised controlled trial $(n=39)$ found that the flavanol EGCG significantly reduced volume of uterine fibroids and improved symptoms of anaemia and blood loss [58•].

The reduction of fibroid volume is attributed in part to the inhibitory action of EGCG on catechol- $O$-methyltransferase (COMT). In comparison to surrounding myometrial tissue, COMT is elevated in uterine fibroids and involved in their pathogenesis [59]. A common genetic variation of COMT is also implicated in cardiovascular disease and high blood pressure $[60,61]$. Furthermore, a reduction of atherosclerotic lesions induced by COMT in animals implies a relationship between EGCG and COMT in the treatment of this disease in humans [62]. 
Table 2 Acupuncture points: heavy periods

\begin{tabular}{|c|c|c|}
\hline \multicolumn{3}{|c|}{ Acupuncture points for heavy periods resulting from blood stasis } \\
\hline Channel name and number & Pinyin & $\begin{array}{l}\text { Actions associated with traditional } \\
\text { use }\end{array}$ \\
\hline Gall bladder 34 & Yang Ling Quan & Moves blood \\
\hline Ren 6 & Qihai & Moves blood \\
\hline Spleen 10 & Xuehai & Invigorates blood \\
\hline Bladder 17 & Geshu & Invigorates blood \\
\hline Stomach 29 & Guilai & $\begin{array}{l}\text { Invigorates blood in the lower } \\
\text { abdomen }\end{array}$ \\
\hline Liver 3 & Taichong & Invigorates liver blood \\
\hline Spleen 6 & Sanyinjiao & Invigorates liver blood \\
\hline Liver 8 & Qu Quan & Nourishes blood \\
\hline Stomach 36 & Zusanli & Nourishes blood \\
\hline Bladder 20 & Pishu & Nourishes blood \\
\hline $\begin{array}{l}\text { Penetrating vessel spleen } 4+ \\
\text { pericardium } 6\end{array}$ & $\begin{array}{l}\text { Gongsun }+ \text { Neiguan, } \\
\text { respectively }\end{array}$ & Regulates blood \\
\hline
\end{tabular}

Maciocia [69] and Deadman et al. [70]

\section{Acupuncture}

TCM is a system of medicine with several therapies, of which TCM acupuncture is the most popular in literature. In the 1950s, electro-acupuncture was introduced to TCM. There is an abundance of evidence that acupuncture modulates a wide range of endocrinological, neurohormonal, immunological, paracrine and autocrine factors [63-65].

Acupuncture acts on a variety of therapeutic targets associated in the pathogenesis and symptomatology of fibroids. It is effective treatment for dysfunctional bleeding and chronic pelvic inflammatory disease and dysmenorrhoea [66-68] (see Table 2 for acupuncture points used in the treatment of heavy periods).

Stener-Victorin suggested that stimulation of afferent nerve fibres may be one of the mechanisms that acupuncture exerts its effects. Such stimulation would inhibit sympathetic outflow at the spinal level. Furthermore, acupuncture also causes secretion of sensory neurotransmitters, such as substance $\mathrm{P}$ and calcitonin gene-related peptide (CGRP), which may effect neuronal transmission. Nerve impulses (action potentials) usually travel away from the nerve cell body, along the axon, to

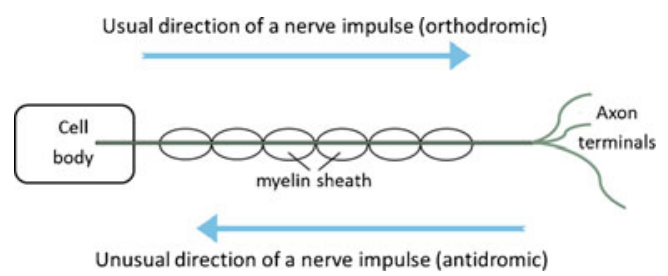

Fig. 1 Nerve impulses (also known as an action potentials) usually travel from the cell body to the axon terminals (orthodromic). In some cases, nerve impulses travel from the axon terminals towards the cell body (antidromic) the axon terminals, from which the impulses are conveyed (to a subsequent neuron). This usual direction of travel is termed orthodromic. However, because acupuncture induces the secretion of sensory neuromodulators, an effect of acupuncture may induce nerve impulses to travel in the opposite direction, that is, away from the axon terminals towards the cell body. This opposite direction of travel is termed anti-dromic and may be another mechanism by which acupuncture modulates the central nervous system [71, 72] (see Fig. 1).

Whether these effects seen in mixed populations translates into improvements in bleeding and pain symptoms associated with fibroids per se remains to be seen.

Acupuncture treatments are effective in improving outcomes in overweight and obese patients. Results from animal experiments have found that acupuncture treatments reduce appetite and affect satiety at the level of the hypothalamus, thus implicating a role of energy homeostasis neurohormones such as leptin in the management of appetite by acupuncture [73]. This effect may also be a result of the pro-inflammatory cytokine downregulation involved in acupuncture treatments [74].

Both manual acupuncture and low-frequency electroacupuncture (LFEA) can lower leptin and raise adiponectin secretion $[75,76]$.

\section{Acupuncture and Infertility}

The role of fibroids in causation of infertility is controversial. Fibroids in certain locations and sizes have been shown to lower success rates. On the other hand, irrespective of cause, infertility and its treatments result in significant stress and anxiety to patients. Women are more likely to experience guilt and hostility than fertile women, and treatment can lead to clinical anxiety and depression [77]. 
Fertility-related stress may also negatively affect IVF treatment [78•]. Trials have also shown that acupuncture significantly alleviates depression, anxiety and stress by modulating both specific and non-specific neurological signalling and also neuromodulators such as cortisol, prolactin, epinephrine and beta endorphin $[79,80]$.

The effect of acupuncture treatments for IVF/ICSI has been examined during the last decade. Whilst some trials have found significant increases in clinical pregnancy and live birth rates when acupuncture is integrated with IVF, the results of meta-analyses are inconclusive due to methodological differences and heterogeneity of populations studied [81-84]. In addition, placebo acupuncture may not be inert, which may explain some of the differences between placebo-controlled trials involving acupuncture [85].

A variety of mechanisms have been proposed to explain the anti-fertility effects of uterine fibroids. Of particular interest to CAM is an increase in myometrial contractility observed with fibroids during implantation and increase in conception rates following myomectomy in women with two or more peristaltic movements in $3 \mathrm{~min}$ [86].

A potential candidate marker for effectiveness of acupuncture therapy is the vasoactive modulator, CGRP, which is upregulated during the window of implantation [87]. CGRP inhibits angiotensin II and relaxes smooth muscle in the uterus [88]. Modulation of CGRP by acupuncture may inhibit uterine contractions associated with fibroids, and a trial investigating this is underway at our centre.

\section{Suggested Approach to the Management of Uterine Fibroids}

An integrated approach using both CM and CAM is essential in providing holistic and safe and effective treatment $[89,90]$. Following referral, a detailed history is taken including lifestyle, diet, family history, and signs and symptoms relating to TCM. The results of any previous investigations and treatments including $\mathrm{CM}$ are also reviewed. It is best practice that the diagnosis of fibroids is established using conventional medicine.

Therapeutic options depend on the outcome of consultation, investigations, interdisciplinary discussions and patient choice. CAM treatment may involve herbal, acupuncture and dietary/lifestyle choices. Insofar as CAM treatments are selected, CHM is the treatment of choice to reduce volume of uterine fibroids, and, for management of chronic conditions, whereas acupuncture is more efficient in the management of acute conditions, probably due to its modulation of neurohormones such as beta endorphins, leptin and other biochemicals. The increased frequency of acupuncture treatments potentiates the effects of acupuncture, and so, the therapy can also be used in the treatment of chronic conditions.
During the course of treatments, other problems may arise and it is important to treat what is presented by the patient at that time.

\section{Conclusion}

A variety of CAM therapies are available, and there is an urgent need to subject them to academic rigour. A clear understanding of underlying mechanistic pathways and patient's symptoms and needs is crucial in planning individualised therapies. An integrated CM CAM model is likely to yield better patient outcomes and reduced health care costs.

Acknowledgments Open access for this article was funded by King's College London.

\section{Compliance with Ethical Standards}

Conflict of Interest Nick Dalton-Brewer declares no conflict of interest.

Human and Animal Rights and Informed Consent This article does not contain any studies with human or animal subjects performed by any of the authors.

Open Access This article is distributed under the terms of the Creative Commons Attribution 4.0 International License (http:// creativecommons.org/licenses/by/4.0/), which permits unrestricted use, distribution, and reproduction in any medium, provided you give appropriate credit to the original author(s) and the source, provide a link to the Creative Commons license, and indicate if changes were made.

\section{References}

Papers of particular interest, published recently, have been highlighted as:

- Of importance

- Of major importance

1. Wieland LS, Manheimer E, Berman BM. Development and classification of an operational definition of complementary and alternative medicine for the Cochrane collaboration. Altern Ther Health Med. 2011;17(2):50-9.

2. nccih.nih.gov. Last updated March 2105; accessed 10 February 2016.

3. Zhang Y, Leach MJ, Hall H, Sundberg T, Ward L, Sibbritt D, Adams J; Differences between male and female consumers of complementary and alternative medicine in a national US population: a secondary analysis of 2012 NIHS data. Evid Based Complement Alternat Med. 2015:413173.

4. Kronenberg F, Cushman LF, Wade CM, Kalmuss D, Chao MT. Race/ethnicity and women's use of complementary and alternative medicine in the United States: results of a national survey. Am J Public Health. 2006;96(7):1236-42. 
5. Peter KP, Baars E. Patients whose GP knows complementary medicine tend to have lower costs and live longer. Eur J Health Econ. 2012;13(6):769-76.

6. The Commonwealth Fund. In: Falik M, Collins K, editors. The Commonwealth Fund Survey of Women's Health: selected facts on U.S. women's health. Baltimore: Johns Hopkins University Press; 1996.

7. Wise LA, Palmer JR, Harlow BL, et al. Risk of uterine leiomyomata in relation to tobacco, alcohol and caffeine consumption in the Black Women's Health Study. Hum Reprod. 2004;19:1746-54.

8. Wise LA, Radin RG, Palmer JR, Kumanyika SK, Rosenberg L. A prospective study of dairy intake and risk of uterine leiomyomata. Am J Epidemiol. 2010;171(2):221-32.

9. Wise LA, Radin RG, Palmer JR, Kumanyika SK, Boggs DA, Rosenberg L. Intake of fruit, vegetables, and carotenoids in relation to risk of uterine leiomyomata. Am J Clin Nutr. 2011;94(6):1620 31.

10. van Erp-Baart MA, Brants HA, Kiely M, et al. Isoflavone intake in four different European countries: the VENUS approach. Br J Nutr. 2003;89 Suppl 1:S25-30.

11. Messina M, Nagata C, Wu AH. Estimated Asian adult soy protein and isoflavone intakes. Nutr Cancer. 2006;55(1):1-12.

12. Ha H, Lee YS, Lee JH, Choi H, Kim C. High performance liquid chromatography analysis of isoflavones in medicinal herbs. Arch Pharm Res. 2006;29:96.

13. Heber D, Berdanier CD, Dwyer JT, Feldman EB, eds. Plant foods and phytochemicals in human health. CRC Press. 2008:176-81.

14. Claudine Manach C, Scalbert A, Morand C, Rémésy C, Jiménez L. Polyphenols: food sources and bioavailability. Am J Clin Nutr. 2004;79(5):727-47.

15. Kim D-I, Lee T-K, Lim I-S, Kim H, Lee Y-C, Kim C-H. Regulation of IGF-I production and proliferation of human leiomyomal smooth muscle cells by Scutellaria barbata D. Don in vitro: isolation of flavonoids of apigenin and luteolin as acting compounds. Toxicol Appl Pharmacol. 2005;205(3):213-24.

16. Jeong JH, An LY, Kwon YT, Rhee JG, Lee YJ. Effects of low dose quercetin: cancer cell-specific inhibition of cell cycle progression. $\mathrm{J}$ Cell Biochem. 2009;106(1):73-82.

17. National Institutes of Health office of dietary supplements; Vitamin D fact sheet for consumers. Reviewed June 2011.

18. Halder S, Sharan C, Hendy A. 1,25-Dihydroxyvitamin D3 treatment shrinks uterine leiomyoma tumors in the Eker rat model. Biol Reprod. 2012;86(4) (Article 116):1-10.

19.• Sabry M, Halder SK, Allah ASA, Roshdy E, Rajaratnam V, AlHendy A. Serum vitamin $\mathrm{D}_{3}$ level inversely correlates with uterine fibroid volume in different ethnic groups: a cross-sectional observational study. Int J Womens Health. 2013;5:93-100. This is a good cross-sectional study, correlating uterine fibroid volume in different ethnic groups and the use and availability of vitamin $D$. It also highlights potential implications in differences between race and socioeconomic groups.

20. Thompson ME, Racine EF. Serum micronutrient concentrations and risk for uterine fibroids. J Womens Health (Larchmt). 2011;20(6):915-22.

21. Adam TC, Epel ES. Stress, eating and the reward system. Psychol Behav. 2007;91:449-58

22. Dalman M. Stress-induced obesity and the emotional nervous system. Trends Endocrinol Metab. 2010;21(3):159-65.

23. Vines AI, Ta M, Esserman DA. The association between selfreported major life events and the presence of uterine fibroids. Womens Health Issues. 2010;20:294-8.

24. Vines AI, Nguyen TTX, Ta M, Esserman D, Baird DD. Selfreported daily stress, squelching of anger and the management of daily stress and the prevalence of uterine leiomyomata: the ultrasound screening study. Stress Health. 2011;27:e188-94.
25. Dallman MF, Pecoraro N, Akana SF, la Fleur SE, Gomez F, Houshyar H, et al. Chronic stress and obesity: a new view of “comfort food". Proc Natl Acad Sci U S A. 2003;100(11):696-701.

26. DeFronzo R, Ferrannini E. Insulin resistance: a multifaceted syndrome responsible for NIDDM, obesity, hypertension, dyslipidemia, and atherosclerotic cardiovascular disease. Diabetes Care. 1991;14(3):173-94.

27. Hocutt JE. Uterine fibroids and hypertension. Del Med J. 1979;51: 697-9.

28. Faerstein E, Szklo M, Rosenshein NB. Risk factors for uterine leiomyoma: a practice-based case-control study. II. Atherogenic risk factors and potential sources of uterine irritation. Am J Epidemiol. 2001;153(1):11-9.

29. Boynton-Jarrett R, Rich-Edwards J, Malspeis S, Missmer SA, Wright R. A prospective study of hypertension and risk of uterine leiomyomata. Am J Epidemiol. 2005;161:628-38.

30. He Y, Zeng Q, Li X, Liu B, Wang P. The association between subclinical atherosclerosis and uterine fibroids. PLoS One. $2013 ; 8(2)$, e 57089 . This is a good study evaluating a range of possible candidate markers of uterine fibroids and potential correlation with atherosclerosis.

31. Eisinger S. Uterine fibroids; National Women's Health Information Centre. US Department of Health and Human Services Office on Women's Health. Womens' health.gov;Last updated May 13, 2008. Accessed 23/03/2016

32. Shikora SA, Niloff JM, Bistrian BR, Forse RA, Blackburn GL. Relationship between obesity and uterine leiomyomata. Nutrition. 1991;7(4):251-5.

33. Summers WE, Watson RL, Wooldridge WH, et al. Hypertension, obesity and fibromyomata uteri, as a syndrome. Arch Intern Med. $1971 ; 128: 750-4$.

34. Takeda T, Sakata M, Isobe A, Miyake A, Nishimoto F, Ota Y, et al. Relationship between metabolic syndrome and uterine leiomyomas: a case-control study. Gynecol Obstet Invest. 2008;66:14-7.

35. Matsumoto T, Sagawa N, Mukoyama M, Tanaka I, Itoh H, Goto M, et al. Type 2 angiotensin II receptor is expressed in human myometrium and uterine leiomyoma and is down-regulated during pregnancy. J Clin Endocrinol Metab. 1996;81(12):4366-72.

36. Kalupahana NS, Moustaid-Moussa N. The renin-angiotensin system: a link between obesity, inflammation and insulin resistance. Obes Rev. 2012;13(2):136-49.

37. Rüster $\mathrm{C}$, Wolf $\mathrm{G}$. The role of the renin-angiotensin-aldosterone system in obesity-related renal diseases. Semin Nephrol. 2013;33(1):44-53.

38. Chen HS, Chan TF, Chung YF, Yuan SF. Aberrant serum adiponectin levels in women with uterine leiomyomas. Gynecol Obstet Invest. 2004;58(3):160-3.

39. Ouchi N, Kihara S, Arita Y, et al. Novel modulator for endothelial adhesion molecules: adipocyte-derived plasma protein adiponectin. Circulation. 1999;100:2473-6.

40. Sacks FM, Vetkey LP, Ollmer WM, Appel LJ, Brya GA, Harsha D, et al. Effects on blood pressure of reduced dietary sodium and the dietary approaches to stop hypertension (DASH) diet. N Engl J Med. 2001;344(1):3-10.

41. CJ, McCulloch M, Smikle C, Gao J. Chinese herbal medicine and clomiphene citrate for anovulation: a meta-analysis of randomized controlled trials. J Altern Complement Med. 2011;17(5):397-405.

42. Yen H-R, Chen Y-Y, Huang T-P, Chang T-T, Tsao J-Y, Chen B-C, et al. Prescription patterns of Chinese herbal products for patients with uterine fibroid in Taiwan: a nationwide population-based study. J Ethnopharmacol. 2015;171(2):223-30.

43. Chen N-N, Han M, Yang H, Yang G-Y, Wang Y-Y, Wu X-K, et al. Chinese herbal medicine Guizhi Fuling formula for treatment of uterine fibroids: a systematic review of randomised clinical trials. 
BMC Complement Altern Med. 2014;14:2. This is a good systematic review, illustrating the benefits of an integrated approach in the treatment of uterine fibroids.

44. Xu W, Zhong W, Liu J, Liu H, Zhu B. Study on anti-tumor effect of total glycosides from Radix paeoniae rubra in S180 tumor-bearing mice. Afr J Tradit Complement Altern Med. 2013;10(3):580-5.

45. Xu H, Chen Z, Zhou L, Niu J. Study total glucosides of Radix paeoniae rubra induced K562 tumor cell apoptosis of signalling pathways and related gene changes. Zhongguo Zhong Yao Za Zhi. 2010;35(24):3377-81

46. Kwon HY, Hong SP, Hahn DH, Kim JH. Apoptosis induction of Persicae Semen extract in human promyelocytic leukemia (HL-60) cells. Arch Pharm Res. 2003;26(2):157-61.

47. Leung PC, Koon CM, Lau CB, Chook P, Cheng WK, Fung KP, et al. 10 years research on a cardiovascular tonic: a comprehensive approach - from quality control and mechanisms of action to clinical trial. Evid Based Complement Alternat Med. 2013;2013: 319703.

48. Wu B, Liu M, Zhang S. Dan Shen agents for acute ischaemic stroke. Cochrane Database of Systematic Reviews. 2007;2(Art. No. CD004295)

49. Sieveking DP, Woo KS, Fung K, Pia Lundman P, Nakhla S, Celermajer D. Chinese Herbs Dan Shen and Gegen modulate key early atherogenic events in vitro. Int J Cardiol. 2005;105(1):40-5.

50. Si H, Liu D. Phytochemical genistein in the regulation of vascular function: new insights. Curr Med Chem. 2007;14(24):2581-9.

51. Nakashima S, Koike T, Nozawa Y. Genistein, a protein tyrosine kinase inhibitor, inhibits thromboxane A2-mediated human platelet responses. Mol Pharmacol. 1991;39(4):475-80.

52. Jing Guo J, Zheng L, Chen L, Luo N, Yang W, Qu X, et al. Lipopolysaccharide activated TLR4/NF-KB signaling pathway of fibroblasts from uterine fibroids. Int J Clin Exp Pathol. 2015;8(9): 10014-25.

53. Yang TY, Wei JC, Lee MY, Balance CM, Chen CM, Ueng KC. A randomized, double-blind, placebo-controlled study to evaluate the efficacy and tolerability of Fufang Danshen (Salvia miltiorrhiza) as add-on antihypertensive therapy in Taiwanese patients with uncontrolled hypertension. Phytol Res. 2012;26(2):291-8.

54. Tang FT, Cao Y, Wang TQ, Wang LJ, Guo J, Zhou XS, et al. Tanshinone IIA attenuates atherosclerosis in $\operatorname{ApoE}(-/-)$ mice through down-regulation of scavenger receptor expression. Eur $\mathrm{J}$ Pharmacol. 2011;650(1):275-84

55. Chang CC, Chu CF, Chao-Nin Wang CN, Wu HT, Bi KW, Pang JS, et al. The anti-atherosclerotic effect of tanshinone IIA is associated with the inhibition of TNF- $\alpha$-induced VCAM-1, ICAM- 1 and CX3CL1 expression. Phytomedicine. 2014;21(3):207-16.

56. Wu GB, Zhou EX, Qing DX. Tanshinone IIA elicited vasodilation in rat coronary arteriole: roles of nitric oxide and potassium channels. Eur J Pharmacol. 2009;617(1-3):102-7.

57. Li X, Du JR, Yu Y, Bai B, Zheng XY. Tanshinone IIA inhibits smooth muscle proliferation and intimal hyperplasia in the rat carotid balloon-injured model through inhibition of MAPK signaling pathway. J Ethnopharmacol. 2010;129(2):273-9.

58. Roshdy E, Rajaratnam V, Maitra S, Sabry M, Allah ASA, Al-Hendy A. Treatment of symptomatic uterine fibroids with green tea extract: a pilot randomized controlled clinical study. Int J Womens Health. 2013;5:477-86. This is a well designed trial, demonstrating the benefit of nutraceutical approach in the treatment of uterine fibroids.

59. Al-Hendy A, Salama SA. Catechol-O-methyltransferase polymorphism is associated with increased uterine leiomyoma risk in different ethnic groups. J Soc Gynecol Investig. 2006;13(2):136-44.

60. Hagen K, Stovner LJ, Skorpen F, Pettersen E, Zwart JA. The impact of the catechol-O-methyltransferase Val158Met polymorphism on survival in the general population - the HUNT study. BMC Med Genet. 2007;8:34.
61. Hall KT, Nelson CP, Davis RB, Buring JE, Kirsch I, Mittleman MA, et al. Polymorphisms in catechol-O-methyltransferase modify treatment effects of aspirin on risk of cardiovascular disease. Arterioscler Thromb Vasc Biol. 2014;34(9):2160-7.

62. Auclair S, Milenkovic D, Besson C, Chauvet S, Gueux E, Morand $\mathrm{C}$, et al. Catechin reduces atherosclerotic lesion development in ApoE-deficient mice: a transcriptomic study. Atherosclerosis. 2009;204(2):e21-7.

63. Ma S-X. Neurobiology of acupuncture: toward CAM. Evid Based Complement Alternat Med. 2004;1(1):41-7.

64. Zhao Z-Q. Neural mechanism underlying acupuncture analgesia. Prog Neurobiol. 2008;85(4):355-75.

65. Ho ZH, Hwang SC, Wong EK, et al. Neural substrates, experimental evidences and functional hypothesis of acupuncture mechanisms. Acta Neurol Scand. 2006;113:370-7.

66. The British Acupuncture Council. Gynaecology and acupuncture: evidence for effectiveness; dysmenorrhoea. Feb 2015. Accessed 02 Feb 2016.

67. Cho S-H, Hwang E-W. Acupuncture for primary dysmenorrhoea: a systematic review. BJOG. 2010;117(5):509-21.

68. Proctor M, Farquhar C, Stones W, He L, Zhu X, Brown J. Transcutaneous electrical nerve stimulation for primary dysmenorrhoea. Cochrane Database of Systematic Reviews 2002, Issue 1. Art. No.: CD002123. doi: 10.1002/14651858.CD002123.

69. Maciocia G. Obstetrics and gynaecology in Chinese medicine. Churchill Livingstone; London: 1998.

70. Deadman P, Al-Khafaji M, Baker K. A Manual of acupuncture. Hove, Brighton: Journal of Chinese Medicine Publications; 1998.

71. Stener Victorin E, Waldenstrom U, Andersson S, Wikland M. Reduction of blood flow impedance in the uterine arteries of infertile women with electro-acupuncture. Hum Reprod. 1996;11(6): 1314-7.

72. Kashiba H, Uedo Y. Acupuncture to the skin induces release of substance $\mathrm{P}$ and calcitonin gene-related peptide from peripheral terminals of primary sensory neurons in the rat. Am J Chin Med. 1991;19:189.

73. Shiraishi T, Onoe M, Kojima T, Sameshima Y, Kageyama T. Effects of auricular stimulation on feeding-related hypothalamic neuronal activity in normal and obese rats. Brain Res Bull. 1995;36(2):141-8.

74. McDonald JL, Cripps AW, Smith PK, Smith CA, Xue CC, Golianu B. The anti-inflammatory effects of acupuncture and their relevance to allergic rhinitis: a narrative review and proposed model. Evid Based Complement Alternat Med. 2013;2013:591796.

75. Luo HL, Li RH. Effect of electroacupuncture on leptin and adiponectin in simple obesity patients. Zhen Ci Yan Jiu. 2007;32(4):264-7.

76. Xu B, Yuan J-h, Liu Z-c, Lu Y-n, Wang X-j, Chen M, et al. Clinical observation of adiponectin in inhibiting fatty toxicity by acupuncture. J Acu Tui. 2006;4(4):206-10.

77. Glover I, Novakovic A, Hunter MS. An exploration of the nature and causes of distress in women attending gynecology outpatient clinics. J Psych Obs Gyn. 2002;23(4):237-48.

78. Louis GM, Lum KJ, Sundaram RS, Chen Z, Kim S, Lynch C, et al. Stress reduces conception probabilities across the fertile window: evidence in support of relaxation. Fertil Steril. 2011;95(7):2184-9. This well thought out cohort study provides good evidence demonstrating the effect of increased sympathetic medullar system activity in fertility.

79. Wang H, Qi H, Wang B, Cui Y, Zhu L, Rong Z, et al. Is acupuncture beneficial in depression: a meta-analysis of 8 randomized controlled trials? J Affect Disord. 2008;111(2-3):125-34.

80. Margarelli PC, Cridennda DK. Acupuncture and IVF poor responders: a cure? Fertil Steril. 2004;81 Suppl 3:20.

81. Paulus WE, Zhang M, Strehler E, El-Danasouri I, Sterzik K. Influence of acupuncture on the pregnancy rate in patients who 
undergo assisted reproduction therapy. Fertil Steril. 2002;77(4):721-4.

82. Westergaard LG, Mao Q, Krogslund M, Sandrini S, Lenz S, Grinsted J. Acupuncture on the day of embryo transfer significantly improves the reproductive outcome in infertile women: a prospective, randomized trial. Fertil Steril. 2006;85(5):1341-6.

83. Manheimer E, Zhang G, Udoff L, et al. Effects of acupuncture on rates of pregnancy and live birth among women undergoing in vitro fertilisation: systematic review and meta-analysis. BMJ. 2008;336(7643):545-9.

84. El-Toukhy T, Sunkara SK, Khairy M, Dyer R, Khalaf Y, Coomarasamy A. A systematic review and meta-analysis of acupuncture in in vitro fertilisation. BJOG. 2008;115(10):1203-13.

85. So EW, Ng EH, Wong YY, Lau EY, Yeung WS, Ho PC. A randomized double blind comparison of real and placebo acupuncture in IVF treatment. Hum Reprod. 2009;24(2):341-8.
86. Yoshino M, Wang SY, Kao CY. Sodium and calcium inward currents in freshly dissociated smooth myocytes of rat uterus. J Gen Physiol. 1997;110:565-77.

87. Dong Y, Reddy DM, Green KE, Chauhan MS, Wang HQ, Nagamani M, et al. Calcitonin gene-related peptide (CALCA) is a proangiogenic growth factor in the human placental development. Biol Reprod. 2007;76(5):892-9.

88. Samuelson UE, Dalsgaard CJ, Lundberg JM, Hökfelt T. Calcitonin gene-related peptide inhibits spontaneous contractions in human uterus and fallopian tube. Neurosci Lett. 1985;62(2):225-30.

89. Ham C, Curry N. Integrated care; The King's Fund 2011; kingsfund.org.uk. Accessed 03 February 2016.

90. National Cancer Institute cancer.gov. Accessed 03 Feb 2016. 